\title{
Energy Consumption in the Food Service Industry: A Conceptual Model of Energy Management Considering Service Properties
}

\author{
Tomomi Nonaka ${ }^{1}$, Takeshi Shimmura ${ }^{2}$, Nobutada Fujii ${ }^{3}$, and Hajime Mizuyama ${ }^{1}$ \\ ${ }^{1}$ Dept. of Industrial and Systems Engineering, Aoyama Gakuin University, \\ 5-10-1 Fuchinobe, Chuo-ku Sagamihara-shi, Kanagawa 252-5258, Japan \\ ${ }^{2}$ Ganko Food Service Co., Ltd. \\ ${ }^{3}$ Graduate School of System Informatics, Kobe University \\ nonaka@ise.aoyama.ac.jp
}

\begin{abstract}
This paper examines features of energy consumption in the food service industry considering the possible effects caused by properties of service such as intangibility, heterogeneity, perishability, and simultaneity. This study examines four food service businesses: restaurant services with a cook-chill system, restaurant services with a cook-serve system, delivery of prepared food services, and home-meal replacements. The service provision process is analysed along with the energy input for each process. Subsequently, a conceptual model of energy demand management considering the simultaneity of service is proposed as a first step goal to enhance energy demand management.
\end{abstract}

Keywords: energy consumption · food service industry $\cdot$ restaurant $\cdot$ service engineering $\cdot$ simultaneity $\cdot$ service production system

\section{Introduction}

The service sector plays a key role in economic activity today. As society becomes more conscious of sustainability, companies are required to conserve energy and natural resources. In the food service industry, which is part of the service sector, life cycle assessment (LCA) is currently expanding to address diverse product groups and production processes $[1,2,3,4,5,6]$. LCA involves cradle-to-grave analyses of production systems and evaluates inputs and outputs in all life cycle processes from upstream to downstream. Schau et al. [1] state that food production has been much more energy intensive because of industrialization. In the food service industry, in addition to the operation's goals to improve efficiency [7,8], centralized efficient operations in central kitchens $[9,10]$, replacement of efficiency-enhancing equipment $[11,12]$, and robots [13] are introduced to save energy.

Energy efficient production systems have been studied predominantly in the manufacturing industry. To improve process planning and operations, detailed changes in energy consumption are evaluated based on a processing condition. In terms of electricity, energy consumption of production machines is normally described as not 
constant over time. Each machine's consumption has its energy profile and is highly dynamic depending on the production process and the actual state of the machine [14]. Power levels during the productive modes of a selective laser sintering machine tool are described by [15]. The load profiles of single machines add up to a cumulative load profile for the process chain and determine the embodied energy of a product [16]. Process chain simulations considering energy profiles of the machines are proposed by [14] and [17]. The energy simulation system [17] provides a function to visually evaluate dynamic changes in the energy consumption per unit of production throughput along a time progression.

Food service businesses provide a service-to-service production system that produce goods/foods. The service production system contains properties of service such as intangibility, heterogeneity, perishability, and/or simultaneity. Few studies, however, consider the properties of service for energy management. It is necessary to consider the possible effects caused by the properties of service in energy consumption and to capture the features of energy consumption. An earlier paper [18] reports to achieve energy saving for quick-service restaurants with an optimized kitchen ventilation system and innovative food preparation/storage technologies. This paper [18] proposes recommended energy efficient measures for quick-service restaurants. Hu et al. [19] investigate the indicators of energy conservation and carbon reduction in restaurants with the aim to promote the development of sustainable food tourism. However, these papers do not consider the effects of the properties of service in service provisions. In addition, the food service industry has several categories such as restaurants, home-meal replacement, delivery service, and so on. These services each have a specific service provision process, so it is expected that the features of energy consumption have different characteristics. Thus, the objective of this research is to examine energy consumption in the food service industry and capture the features of energy consumption considering the properties of service, as well as to propose a conceptual model of energy management as a first step goal to enhance energy demand management.

\section{Energy Consumption in the Food Service Industry}

\subsection{Features of Properties of Service in Energy Consumption}

In this section, the features of energy consumption in the food service industry are examined. It considers the possible effects caused by properties of service such as intangibility, heterogeneity, perishability, and simultaneity. Fig. 1 describes an outline of the energy management system in the food service industry. For energy management, the first step is to visualize and capture the energy consumption feature. Improving energy efficiency and managing energy demand require several approaches, respectively. Improving energy efficiency is realized by reducing energy consumption per a functional unit or its created value. It is required to promote streamlining and/or reduce consumable input energy. On the other hand, energy demand management should consider not only efficiency but also how to operate and standardize energy consumption against the demand peak. 


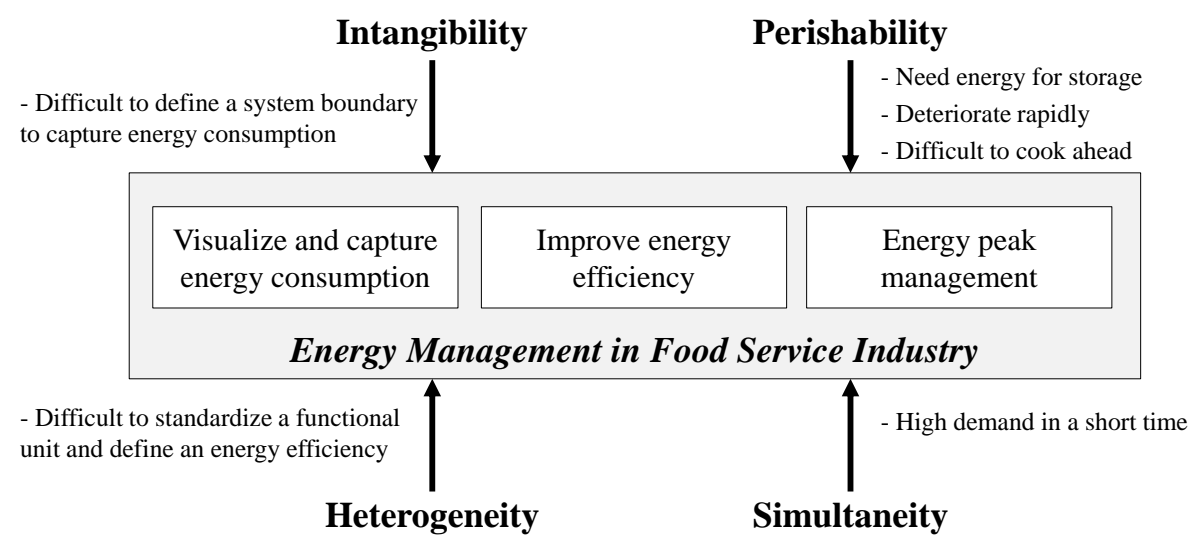

Fig. 1. Outline of Energy Management in the Food Service Industry

Intangibility: The distinction between goods and services in a tangibility continuum classification is discussed by [20]. In the food service industry, dishes and related services are provided, and the dishes can be regarded as tangible goods. Bebko [21] indicates that fast food retailing may certainly fit into the category of differentiated goods/services because tangible food is being offered with the food preparation and delivery service. To capture and evaluate energy consumption accurately, it is necessary to define a system boundary. Intangibility may make it difficult to set the boundary for the evaluation in the service production systems.

Heterogeneity: Generally, in service provision processes, it is difficult to constantly serve produce. In a kitchen in a restaurant, service operations still have many handmade processes that create value [22]. Generally, an index of energy efficiency is evaluated by measuring the amount of energy consumption and its produced value. The heterogeneity of service may lead to difficulty in defining its produced value because of unstandardized functional units.

Perishability: The storage time of food is very short, and food deteriorates rapidly in a large proportion of cases in the food industry, yet it is required to provide a fresh cuisine. Energy is a need for both warm and cold cuisines to keep the food either warm or cool. Further, difficulties in storing premade food inventories lead to the implementation of the build-to-order manufacturing system. A limited cooking operation can be implemented by batch production. Therefore, it has possible effects on energy demand management and controls energy demand.

Simultaneity: A degree of simultaneity in the food services industry is defined according to the location of consumption both spatially and temporally. Introducing a central kitchen system, batch production, and production lead-time can be regarded as influential factors. 
Further, large fluctuations in energy demand occur because the restaurant service has high demand during the lunch and dinner hours. High demand in a short period may make energy demand management hard.

\subsection{Targets}

This paper targets four types of food businesses: (1) restaurant services with cookchill systems, (2) restaurant services with cook-serve systems, (3) delivery of prepared food service, and (4) home-meal replacements. In this paper, a restaurant service with a cook-chill system is referred to as the system that cooks processed foods in the central kitchen. The restaurants with a cook-serve system carry out all of the cooking processes at the restaurant.

An investigation [23] reports the breakdown of energy consumption in a family restaurant located in Japan. In the report, the composition of energy consumption is $30.4 \%$ for cooking, $24.5 \%$ for cooling, $7.3 \%$ for lighting, $18.2 \%$ for hot water supply, and $8.6 \%$ for supply fan. In this paper, cooking processes with major energy consumption are examined.

\subsection{A Breakdown of Energy Consumption}

Fig. 2 shows a service provision process in each of the four businesses: restaurants with a cook-chill system, restaurants with a cook-serve system, delivery service, and home-meal replacements. A pentagon with white colour represents each service production process, and a pentagon with ash colour represents a process of customers. Each process consumes energy, and the amount of consumed energy differs according to the processes and their locations.

In the restaurants with a cook-chill system and a cook-service system, customers order and eat at the restaurant. Restaurants with a cook-chill system can divide cooking processes into a central kitchen and a restaurant, which separates where energy is consumed. Transportation and storing processes both require energy. In the cook-chill system, cook-serve system, and delivery service, major cooking processes are executed right after the customer orders. Therefore, the effects of simultaneity are large. For home-meal replacement services, food is cooked ahead of time at a food processing factory, and final cooking processes are done at the customer's home. The processes are similar to the tangible goods production. From the above, it is described that these four food businesses have several features of energy consumption as well as effects caused by the service properties.

\section{An Energy Peak Management Considering the Service's Simultaneity}

This section proposes a concept of energy demand management with regard to the simultaneity. Energy demand management is useful for energy cost savings, as the electricity rate structures are generally charged according to each consumer's peak 


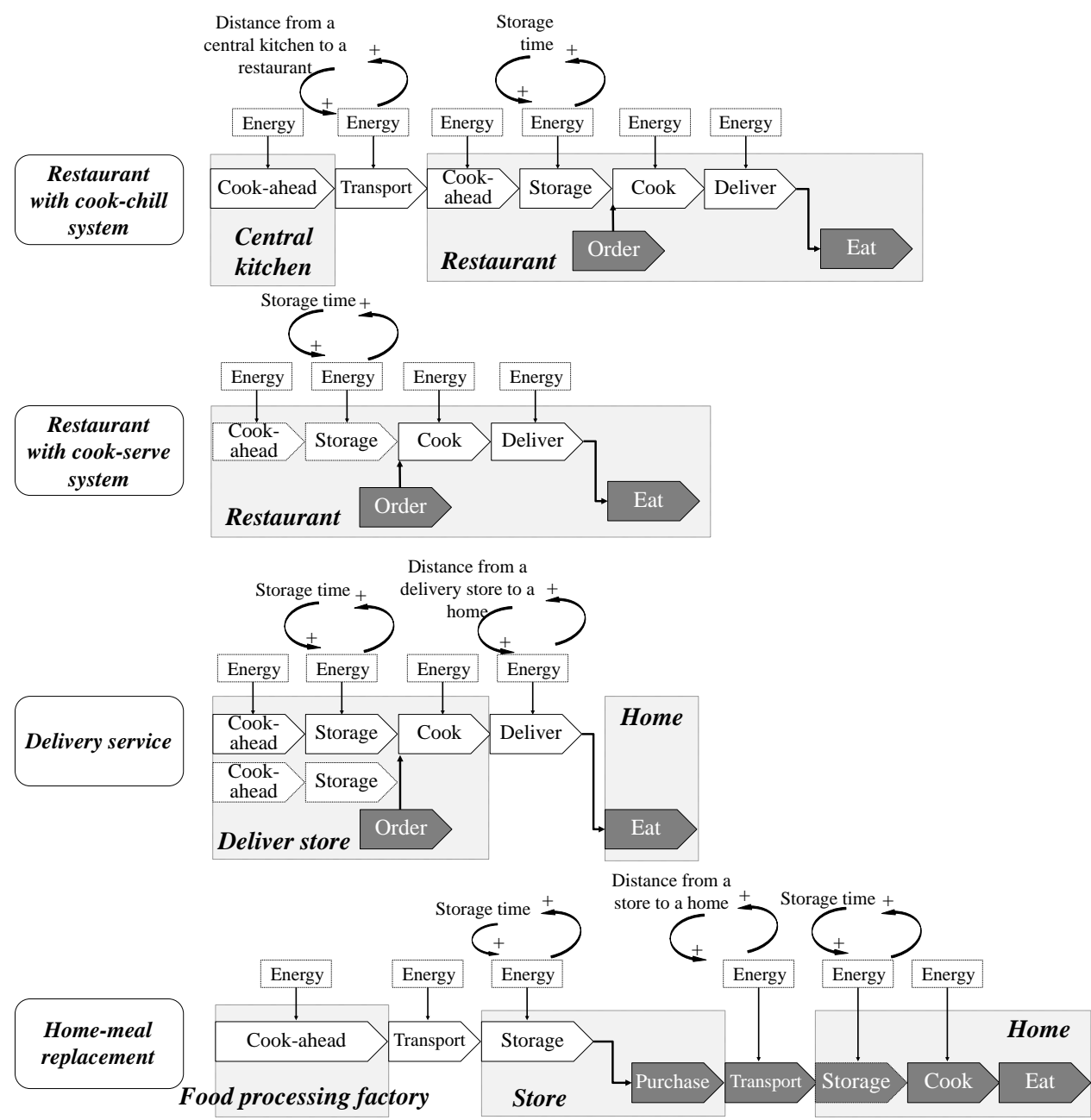

Fig. 2. A Service Provision Process and the Energy Input within the Four Types of Food Service Businesses

demand in the past year. In the food service industry, a cooking process is executed according to demand, and its simultaneity is determined by customer order. Therefore, it is difficult to standardize or shift the demand to control the energy peak. 


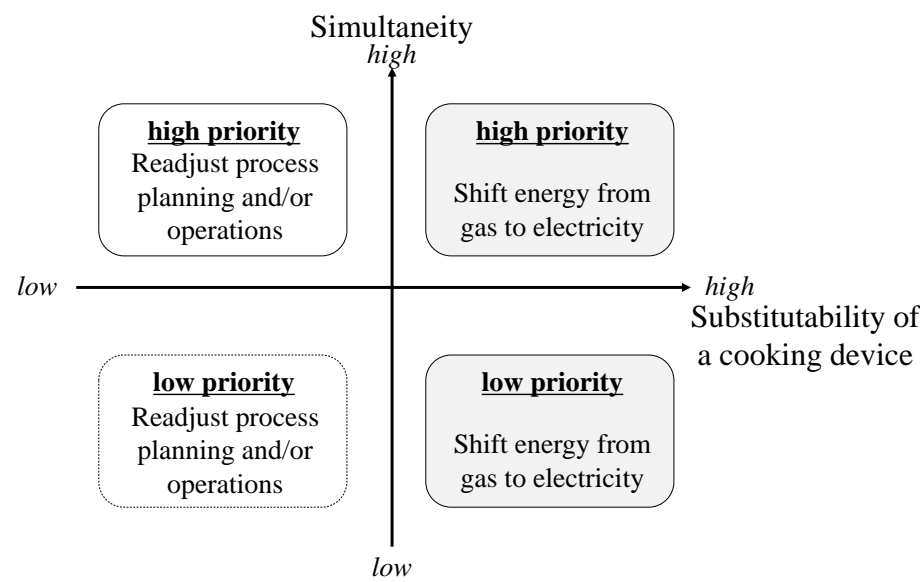

Fig. 3. A Conceptual Model of Energy Demand Management Regarding Simultaneity

Fig. 3 shows a biaxial model for energy demand management to control the energy peaks by changing a device and/or shifting energy sources according to the process. This model focuses on the substitutability of a cooking device and process. Changing cooking and/or energy sources can cause a shift and standardize energy demand in a high demand period.

As shown in Fig. 3, energy management measures are discussed according to the position in the biaxial model. In the first quadrant with high simultaneity and high substitutability of a cooking device, changing a cooking device and/or shifting energy sources of the device are beneficial ways to shift the energy peak. In food service production systems, service operations have many hand-made processes. Therefore, changing devices and/or energy sources can be considered as a feasible way for energy demand management. Some cooking devices such as a steamer, rice cooker, and oven are commercialized, and they use either electricity or gas. These devices can be included as an example to manage operations by changing a device and/or shift an energy source from electricity to gas according to the energy demand. In the second quadrant with high simultaneity and low substitutability of a cooking device, readjusting process planning and/or operations are regarded as a beneficial area for energy management. A measure for the first and second quadrant is a higher priority.

\section{Conclusions}

This paper proposed a conceptual model of energy demand management considering the possible effects caused by properties of service such as intangibility, heterogenei- 
ty, perishability, and simultaneity in the food service industry. Four categories of food service business were examined through their energy consumption features at each service provision process. Developing a more detailed model and verifying the effectiveness of the model are the next steps of this study.

\section{Acknowledgements}

This work was supported in part by JSPS KAKENHI Grant-in-Aid for Young Scientists (B) Number 26730159, JKA and its promotion funds from KEIRINI RACE (27171).

\section{References}

1. Schau, E.M., Fet, A.M: LCA Studies of Food Products as Background for Environmental Product Declarations, International Journal LCA, Vol.13, No.3, pp.255-264, 2008.

2. Andresson, K., Ohlsson, T.: Including Environmental Aspects in Production Development: A Case Study of Tomato Ketchup, LWT - Food Science and Technology, Vol.32, No.3, pp.134-141, 1999.

3. Berlin, J.: Environmental Life Cycle Assessment (LCA) of Swedish Semi-hard Cheese, International Dairy Journal, Vol.12, pp.939-953, 2002.

4. Talve, S.: Life Cycle Assessment of a Basic Lager Beer, International Journal LCA, Vol.6, pp.293-298, 2001.

5. Bengtsson, J., Seddon, J.: Cradle to Retailer or Quick Service Restaurant Gate Life Cycle Assessment of Chicken Products in Australia, Journal of Cleaner Production, Vol.41, pp.291-300, 2013.

6. Righi, S., Oliviero, L., Pedrini, M., Buscaroli, A., Casa, C.C.: Life Cycle Assessment of Management Systems for Sewage Sludge and Food Waste: Centralized and Decentralized Approaches, Journal of Cleaner Production, Vol.44, pp.8-17, 2013.

7. Shimmura, T., Akamatsu, M., Matsunami, H., Takenaka, T., Ohura, S.: Study on Rearrangement of Kitchen Operations to Satisfy Both Work Efficiency and Quality of Dish, Journal of Japan Industrial Management Association (in Japanese), Vol.63, No.4, pp.258266, 2013.

8. Sill, B.: Operations Engineering: Improving Multiunit Operations, Cornell Hotel Restaurant Administration Quarterly, Vol.35, No.3, pp.64-71, 1994.

9. Muller, C.C.: The Business of Restaurant: 2001 and Beyond, International Journal of Hospitality Management, Vol.18, No.4, pp.401-413, 1999.

10. Kubo, S.: A New Cooking System of the Food Service Industry (in Japanese), Journal of Cookery Science of Japan, Vol.30, No.3, pp.285-289, 1997.

11. Jyeshtharaj, B.J., Aniruddha, B.P., Shirish, B.P., Rekha, S.S., Govind, K.B., Kishore, V. M., Bhagwat, A.D., Sanjay, P.D., Arijit, A.G., Ajitkumar, S.G., Prakash, V.C., Yogesh, H. S.: Development of Efficient Designs of Cooking Systems. II. Computational Fluid Dynamics and Optimization, Industrial and Engineering Chemistry Research, Vol.51, No.3, pp.1897-1922, 2001.

12. Deng, S.M., Burnett, J.: A study of energy performance of hotel buildings in Hong Kong, Energy and Buildings, Vol.31, No.1, pp.7-12, 2000. 
13. Suzuki, K.: The Machine: Art of Craftmaster, Journal of the Japan Society of Mechanical Engineers (in Japanese), Vol.111, No.1081, pp.952-953, 2008.

14. Herrmann, C., Thiede, S.: Process Chain Simulation to Foster Energy Efficiency in Manufacturing, CIRP Annals- Manufacturing Technology, Vol.1, No.4, pp. 221-229, 2009.

15. Kellens, K., Yasa, E., Renaldi, W., Dewulf, W., Kruth, J.P., Duflou, J.R.: Energy and Resource Efficiency of SLS/SLM Processes, Proc. International Solid Freeform Fabrication Symposium - An Additive Manufacturing Conference: SFF Symposium 2011, Texas, pp.1-16, 2011.

16. Duflou, J.R., Sutherland, J.W., Dornfeld, D., Herrmann, C., Jeswiet, J., Kara, S., Hauschild, M., Kellens, K.; Towards Energy and Resource Efficient Manufacturing: A Processes and Systems Approach, CIRP Annals- Manufacturing Technology, Vol.61, No.2, pp. 587-609, 2012.

17. Sakuma, T., Hibino, H., Yamaguchi, M.: Manufacturing System Simulation for Evaluation of Productivity and Energy Consumption, Transactions of the Japan Society of Mechanical Engineers Series C (in Japanese), Vol.79, No.798, pp. 178-189, 2013.

18. Hu, M.L., Horng, J.S., Teng, C.C., Chou, S.F.: A Criteria Model of Restaurant Energy Conservation and Carbon Reduction in Taiwan, Journal of Sustainable Tourism, Vol.21, No.5, pp765-779, 2013.

19. The U.S. Department of Energy.: Technical Support Document: 50\% Energy Savings for Quick-Service Restaurants, Pacific Northwest National Laboratory, 2010.

20. Levitt, T.: Marketing Intangible Products and Product intangibles, Harvard Business Review, Vol.59, No.3, pp.94-102, 1981.

21. Bebko, C.P.: Service Intangibility and Its Impact on Consumer Expectations of Service Quality, The Journal of Service Marketing, Vol.14, No.1, pp.9-26, 2000.

22. Shimmura, T., Takenaka, T., Ohura, S.: Improving Labor Productivity and Labor Elasticity at Multiproduct Japanese Cuisine Restaurant Introducing Cell-Production System, Advances in Production Management Systems. Sustainable Production and Service Supply Chains, IFIP Advances in Information and Communication Technology, Vol.415, pp.1117, 2013.

23. Ministry of the Environment of Japan: A Manual of Technology Introduction for Global Warming Countermeasure for Civilian Sector/Operations Division (in Japanese), 2004. 